\title{
Amidoalkyl Naphthols: Trifluoroacetic Acid (TFA) Catalyzed One- Pot, Multi-Component Synthesis
}

\author{
Vinay S. Kadam, Priyanka R. Khanvilkar and Arun L. Patel ${ }^{*}$ \\ Department of Chemistry, Faculty of Science, The Maharaja Sayajirao University of Baroda, Vadodara-390 \\ 002, India
}

\begin{abstract}
Trifluoroacetic acid (TFA) was found as an efficient catalyst for the synthesis of amidoalkyl naphthols from aromatic aldehydes, $\beta$-naphthol and acetamide/benzamide under solvent free condition at $80^{\circ} \mathrm{C}$. All the synthesized compounds were characterized by IR, ${ }^{1} \mathrm{H}$ NMR and Mass spectra. The advantages of the new method were good yields, short reaction times, simple work-up, inexpensive and easily available catalyst and economical due to absence of solvent. Therefore, this method could be an attractive alternative to existing methods for the synthesis of biologically important amidoalkyl naphthols.
\end{abstract}

Keywords: Amidoalkyl naphthols, multicomponent reaction, solvent-free conditions, trifluoroacetic acid.

\section{INTRODUCTION}

In recent years, multicomponent reactions (MCRs) have gained much attention in organic synthesis as they furnish the desired products in a single operation without isolating the intermediates. Thus, reaction times are reduced and energy and raw materials saved [1]. Therefore, researchers have made great efforts to find and develop new MCRs. They have merits over two-component reactions in several aspects including the simplicity of a one-pot procedure, possible structural variations and building up complex molecules.

One of the MCRs is the synthesis of amidoalkyl naphthols, which are ubiquitous to variety of biological important natural product and potent drugs, including a number of nucleoside antibiotic and HIV protease inhibitor, such as ritonavir and lipinavir [2, 3]. Furthermore, amidoalkyl naphthols can be converted in to useful synthetic building block for drugs exhibiting depressor and bradycardiac activities [4, 5]. Amidoalkyl naphthol derivatives have attracted considerable interest because of their pharmaceutical and agricultural activities. For example, 1-aminomethyl-2naphthols have been reported to show cardiovascular activity [4]. The hypotensive and bradycardiac effects of these compounds in normotensive rats as well as their in vitro inotropic and aortic contraction effects in the isolated left atria and aorta of rat have been evaluated. 1-Naphthaleneacetic acid and 2naphthoxyacetic acid have been reported to act as plant-growth regulators $[6,7]$. Looking at the

*Address correspondence to this author at the Department of Chemistry, Faculty of Science, The Maharaja Sayajirao University of Baroda, Vadodara390 002, India; Tel: +91-265-2795552; Fax: +91-265-2792277;

E-mail: arunpatel_5376@yahoo.co.in

E-ISSN: 1929-5030/13 importance of the amidoalkyl naphthols, clean methodologies for them have gained considerable attention.

The preparation of amidoalkyl naphthols can be carried out by multi-component condensation of aryl aldehydes, $\beta$-naphthol and acetonitrile or amide in the presence of Lewis or Bronsted acid catalysts such as Montmorillonite $\mathrm{K} 10$ clay [8], $\mathrm{HClO}_{4}-\mathrm{SiO}_{2}$ [9], lodine [10], $\mathrm{K}_{5} \mathrm{CoW}_{12} \mathrm{O}_{40} .3 \mathrm{H}_{2} \mathrm{O}$ [11], $p$-TSA [12], Sulfamic acid [13], Cation-exchange resins [14], $\mathrm{Fe}\left(\mathrm{HSO}_{4}\right)$ [15], $\mathrm{Sr}(\mathrm{OTf})_{2} \quad$ [16], $\quad \mathrm{Al}\left(\mathrm{H}_{2} \mathrm{PO}_{4}\right)_{3} \quad$ [17], $\mathrm{HClO}_{4}-\mathrm{Al}_{2} \mathrm{O}_{3} \quad$ [18], $\mathrm{NaHSO}_{4} \cdot \mathrm{H}_{2} \mathrm{O} \quad[19], \quad \operatorname{In}(\mathrm{III}) \mathrm{Cl}_{3} \quad$ [20], Zinc benzenesulfonate [21], $\mathrm{PPA}-\mathrm{SiO}_{2}$ [22], $\mathrm{FeCl}_{3} . \mathrm{SiO}_{2}$ [23], $\mathrm{Ce}\left(\mathrm{SO}_{4}\right)_{2}$ [24] and Oxalic acid [25] have been reported. However, some of the reported methods suffer from disadvantages such as prolonged reaction time, higher reaction temperature $\left(>100^{\circ} \mathrm{C}\right)$, low product yields, use of toxic and corrosive solvents, and unconventional methodologies such as microwave or ultrasonic irradiation. Therefore, it was of genuine interest to develop a more universal method for the synthesis of these products. There are several advantages of performing synthesis in solvent-free media such as simple workup, economical due to the absence of solvent and short reaction time.

\section{RESULTS AND DISCUSSION}

Herein, we are reporting a novel protocol for the rapid synthesis of a variety of amidoalkyl naphthols using a catalytic amount of trifluoroacetic acid (TFA) under solvent free condition (Scheme 1).

To optimize the catalyst quantity, a reaction of $p$ nitrobenzaldehyde $(1 \mathrm{mmol}), \beta$-naphthol $(1 \mathrm{mmol})$ and acetamide $(1.3 \mathrm{mmol})$ was selected as a starting reaction. The effect of different amount of catalyst on 


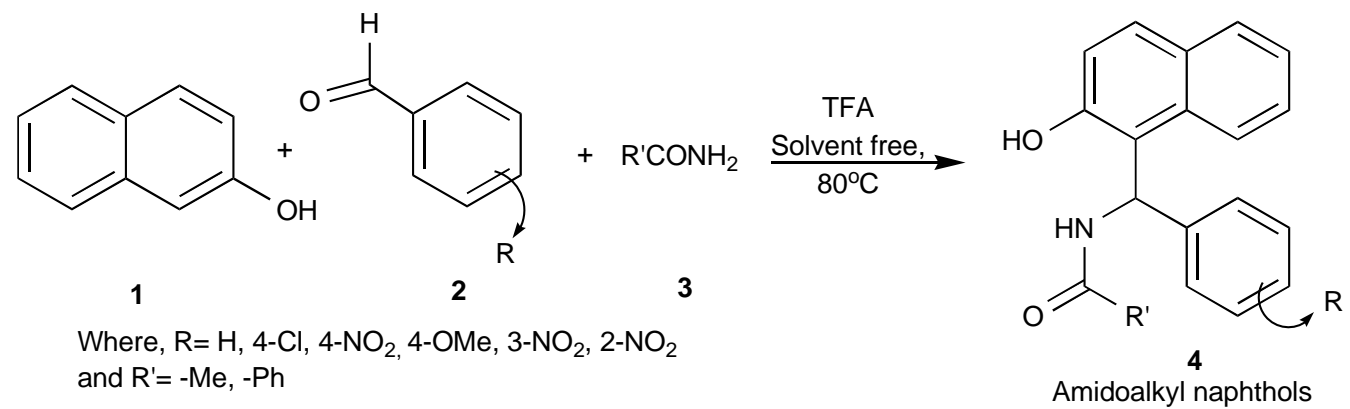

Scheme 1:

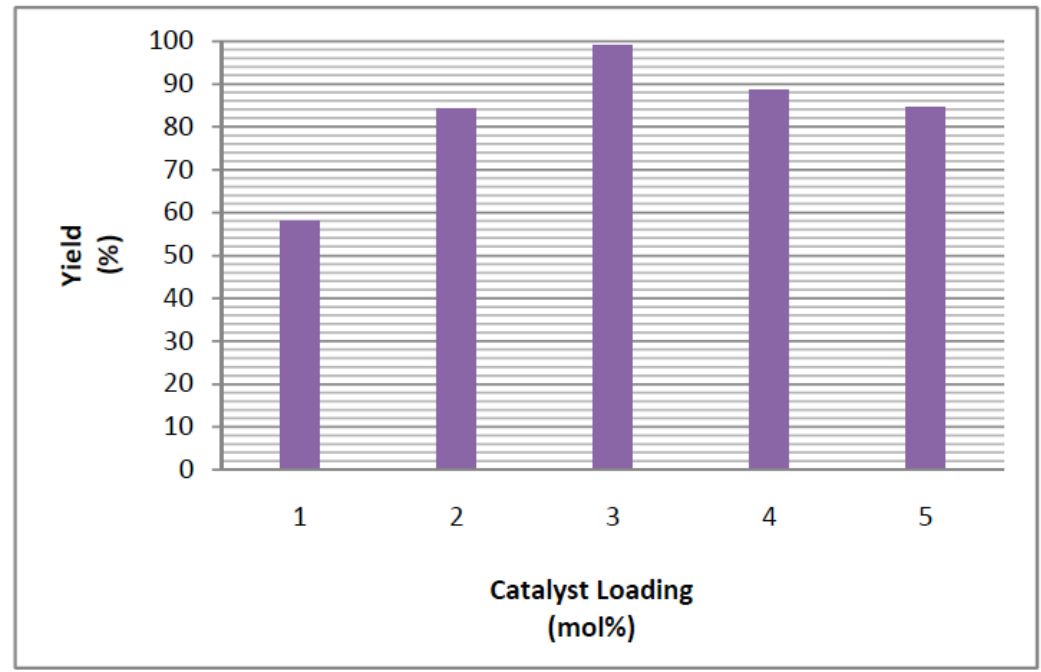

Figure 1: Optimization of Catalyst loading under solvent free condition (Equivalence ratio of Substrate to Catalyst).

the yield of the product has been shown in Figure 1. The perusal of the data shows that $3 \mathrm{~mol} \%$ of TFA gives maximum yield under solvent free condition. Therefore, $3 \mathrm{~mol} \%$ of TFA was selected for further catalytic studies on various similar reactions.

To compare the methodology the same reaction was also carried out in 1,2-dichloroethane at room temperature as well as under reflux condition (15 hrs). The yield of amidoalkyl naphthol was found $5 \%$ and $38 \%$ in former and latter cases, respectively. Furthermore, to enhance the rate of the reaction, the same reaction was carried out under microwave irradiation. Upon irradiation in a microwave for 3 min., 5 min., 7 min., and $10 \mathrm{~min}$., under solvent free condition above reaction gives desired product $22 \%$, $33 \%, 45 \%$ and $36 \%$ yield, respectively. However, the yield was quite high (Table 1 ) in solvent free condition with temperature at $80^{\circ} \mathrm{C}$.

To test the general scope and versatility of this procedure in the synthesis of a variety of substituted amidoalkyl naphthols, we examined a number of substituted aromatic aldehydes, $\beta$-naphthol and acetamide/benzamide. The results are summarized in Table 1. Due to the availability of a vast number of aromatic aldehydes this three component reaction can be very useful to synthesis the desired products. As Table 1 show that in the case of all aromatic aldehydes bearing electron-donating or electron-withdrawing substituent, gave desired amidoalkyl naphthols in good yields. As expected, the aldehydes with electronwithdrawing groups reacted faster than aldehydes having electron-donating groups. In all cases amidoalkyl naphthols were the sole product and no byproduct was observed.

\section{Reaction Mechanism}

As reported in literature, following reaction mechanism was proposed (Scheme 2). The reaction of $\beta$-naphthol with aromatic aldehyde in presence of acid catalyst is known to give an ortho-quinone methide (o$\mathrm{QM})$. The same o-QM, generated in-situ, have been reacted with acetamide via conjugate addition to form amidoalkyl naphthols. Electorn-withdrawing groups on the benzaldehyde in the $o$-QMs intermediates increase the rate of the 1,4-nucleophilic addition reaction 
Table 1: TFA-Catalyzed One-Pot, Multi-Component Synthesis of $\beta$-Naphthol, Aldehydes and Acetamide/Benzamide

\begin{tabular}{|c|c|c|c|c|c|c|}
\hline \multirow{2}{*}{ Entry } & \multirow{2}{*}{$\mathbf{R}$} & \multirow{2}{*}{$\mathbf{R}^{\prime}$} & \multirow{2}{*}{ Product } & \multirow{2}{*}{$\%$ Yield } & \multicolumn{2}{|c|}{ m. p. ${ }^{\circ} \mathrm{C}$} \\
\hline & & & & & Observed & Reported \\
\hline 1 & $\mathrm{H}$ & $\mathrm{Me}$ & $4 a$ & 95 & $240-242$ & $241-243$ [11] \\
\hline 2 & $4-\mathrm{NO}_{2}$ & $\mathrm{Me}$ & $4 b$ & 98 & $246-248$ & $245-247$ [17] \\
\hline 3 & $4-\mathrm{Cl}$ & $\mathrm{Me}$ & $4 c$ & 72 & $235-237$ & $236-238$ [26] \\
\hline 4 & 4-MeO & $\mathrm{Me}$ & $4 d$ & 73 & $184-186$ & $185-187[15]$ \\
\hline 5 & $3-\mathrm{NO}_{2}$ & $\mathrm{Me}$ & $4 e$ & 80 & $254-255$ & $255-256$ [16] \\
\hline 6 & $2-\mathrm{NO}_{2}$ & $\mathrm{Me}$ & $4 f$ & 98 & $217-220$ & $218-220$ [26] \\
\hline 7 & $\mathrm{H}$ & $\mathrm{Ph}$ & $4 \mathrm{~g}$ & 95 & 233-234 & $233-235$ [18] \\
\hline 8 & $4-\mathrm{NO}_{2}$ & $\mathrm{Ph}$ & $4 \mathrm{~h}$ & 92 & $239-241$ & $239-241$ [25] \\
\hline 9 & $4-\mathrm{Cl}$ & $\mathrm{Ph}$ & $4 i$ & 68 & $186-188$ & $187-188$ [16] \\
\hline 10 & $4-\mathrm{MeO}$ & $\mathrm{Ph}$ & $4 j$ & 84 & $206-209$ & $206-208$ [26] \\
\hline 11 & $3-\mathrm{NO}_{2}$ & $\mathrm{Ph}$ & $4 \mathrm{k}$ & 80 & $234-236$ & $233-235$ [27] \\
\hline 12 & $2-\mathrm{NO}_{2}$ & $\mathrm{Ph}$ & $4 \mid$ & 82 & $264-266$ & $266-267$ [26] \\
\hline
\end{tabular}

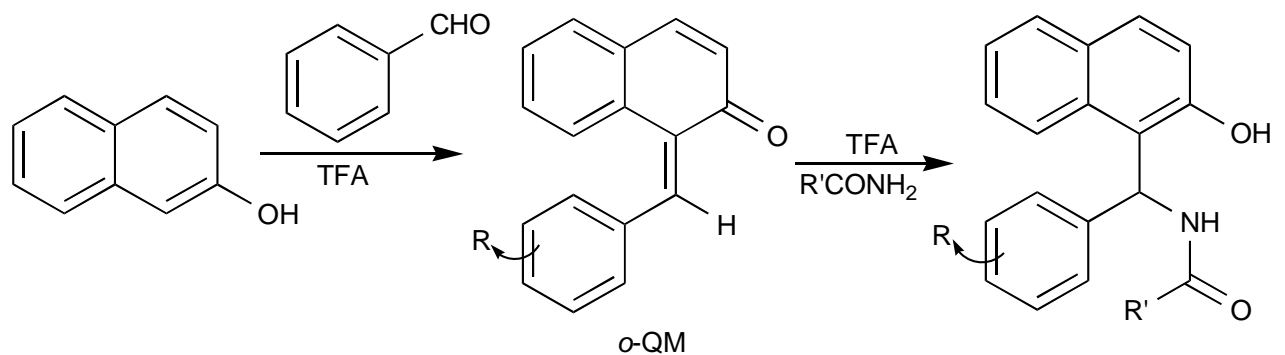

Scheme 2:

because the alkene lowest unoccupied molecular orbital (LUMO) is at lower energy in the presence of electron-withdrawing groups compared with electrondonating grops $[9,22,23]$.

\section{Comparison Results of TFA with other Catalysts Reported in the Literature}

To show the merit of the present work in comparison with reported results in the literature, we compared reactions of TFA with other reported catalyst in the synthesis of $\mathrm{N}$-((2-hydroxynaphthalen-1-yl) (phenyl)methyl)acetamide (4a) and $\mathrm{N}$-((2-hydroxynaphthalen-1-yl)(phenyl)methyl)benzamide (4g). The experimental data shown in Table 2 indicate that TFA can act as an effective catalyst with respect to yields of the products and reaction conditions.

\section{EXPERIMENTAL}

Reagents were purchased from SD Fine, Sisco Research Laboratory (SRL), Qualigens Limited. TLC was performed on Merck $60 \quad F_{254}$ aluminium coated plates and the spots were visualized under UV light. ${ }^{1} \mathrm{H}$ NMR spectra were recorded on Bruker Avance 400 spectrometer in dimethylsulfoxide (DMSO- $\left.d_{6}\right)$. Mass spectra were recorded on Thermo-Fischer DSQ II GCMS instrument. IR spectra were recorded on a Shimadzu Prestige 21 spectrometer. Melting points were recorded in a Thiele's tube using paraffin oil and are uncorrected.

\section{General Procedure for the Synthesis of Amidoalkyl Naphthols}

A mixture of aromatic aldehydes (1 mmol), $\beta$ naphthol $(1 \mathrm{mmol})$, acetamide or benzamide (1.2 $\mathrm{mmol}$ ) and trifluoro acetic acid (TFA) (3 mol \%) was magnetically stirred on a preheated oil bath at $80^{\circ} \mathrm{C}$ under solvent-free condition for one hour. The progress of the reaction was monitored by thin-layer chromatography (TLC). After completion of the reaction, the mixture was cooled to room temperature, washed with $\mathrm{H}_{2} \mathrm{O}$, and the residue was recrystallized from $20 \%$ ethanol. The products were characterized by their m.p. and spectral analysis (IR, ${ }^{1} \mathrm{H}$ NMR, 
Table 2: Comparison Results of TFA with other Catalysts Reported in the Literature

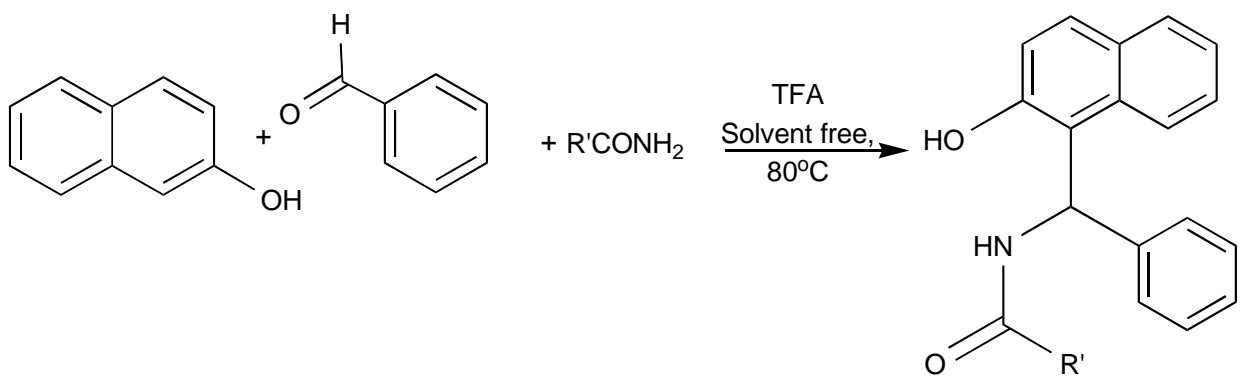

\begin{tabular}{|c|c|c|c|c|c|}
\hline Entry & Amide & Catalyst & Catalyst amount, conditions & Time & $\%$ Yield \\
\hline \multirow[t]{6}{*}{1} & \multirow[t]{6}{*}{ Acetamide } & $\begin{array}{l}\text { Montmorillonite K10 clay } \\
{[8]}\end{array}$ & $0.1 \mathrm{~g}$, solvent free conditions, $125^{\circ} \mathrm{C}$ & $1.5 \mathrm{~h}$ & 89 \\
\hline & & $\mathrm{I}_{2}[10]$ & $5 \mathrm{~mol} \%$, solvent free conditions, $125^{\circ} \mathrm{C}$ & $5.5 \mathrm{~h}$ & 85 \\
\hline & & $\mathrm{K}_{5} \mathrm{CoW}_{12} \mathrm{O}_{40} \cdot 3 \mathrm{H}_{2} \mathrm{O}[11]$ & $1 \mathrm{~mol} \%$; solvent free condition, $125^{\circ} \mathrm{C}$ & $2 \mathrm{~h}$ & 90 \\
\hline & & $\mathrm{HClO}_{4}-\mathrm{Al}_{2} \mathrm{O}_{3}[18]$ & $0.1 \mathrm{~g}\left(0.2 \mathrm{mmol}\right.$ of $\left.\mathrm{H}^{+}\right)$, solvent free conditions, $125{ }^{\circ} \mathrm{C}$ & $30 \mathrm{~min}$ & 90 \\
\hline & & $\mathrm{NaHSO}_{4} \cdot \mathrm{H}_{2} \mathrm{O}[19]$ & $45 \mathrm{mg}$, solvent free conditions, $120^{\circ} \mathrm{C}$ & $11 \mathrm{~min}$ & 86 \\
\hline & & Zincbenzenesulfonate [21] & $0.2 \mathrm{mmol}$, solvent free conditions, $80^{\circ} \mathrm{C}$ & $6.5 \mathrm{~h}$ & 51 \\
\hline \multirow[t]{5}{*}{2} & \multirow[t]{5}{*}{ Benzamide } & $\mathrm{HClO}_{4}-\mathrm{SiO}_{2}[9]$ & $1 \mathrm{~mol} \%$, solvent free conditions, $125^{\circ} \mathrm{C}$ & $10 \mathrm{~min}$ & 90 \\
\hline & & Sulfamic acid [13] & $\begin{array}{l}2.5 \mathrm{mmol} \text {, solvent free conditions, irradiated in the ultrasonic } \\
\text { cleaner at } 30^{\circ} \mathrm{C}\end{array}$ & $24 \min$ & 92 \\
\hline & & Zincbenzenesulfonate [21] & $0.2 \mathrm{mmol}$, solvent free conditions, $80^{\circ} \mathrm{C}$ & $6.5 \mathrm{~h}$ & 84 \\
\hline & & $\mathrm{PPA}^{\mathrm{S}} \mathrm{SiO}_{2}[22]$ & $(0.03 \mathrm{~g}) 1.5 \mathrm{~mol} \%$, solvent free conditions, $120^{\circ} \mathrm{C}$ & $5 \min$ & 80 \\
\hline & & TFA & $3 \mathrm{~mol} \%$, solvent free conditions, $100^{\circ} \mathrm{C}$ & $1 \mathrm{~h}$ & 95 \\
\hline
\end{tabular}

${ }^{a}$ Based on a reaction of benzaldehyde, $\beta$-naphthol and amide.

Mass-spectra) and compared with those of the known compounds. Spectral data for some compounds are as follows.

Compound 4b: N-((4-nitrophenyl)(2-hydroxynaphthalen-1-yl)methyl)acetamide

Yield: $98 \%$, Yellow solid. m.p. $246-248^{\circ} \mathrm{C}$, IR $(\mathrm{KBr})$ : v 3391, 3267, 2593, 1648, 1603, 1522, 1438, 1063, 825, 739, $447 \mathrm{~cm}^{-1}$. ${ }^{1} \mathrm{H}$ NMR: $\left(400 \mathrm{MHz}\right.$, DMSO- $\left.d_{6}\right): \delta$ $2.02\left(\mathrm{~s}, 3 \mathrm{H},-\mathrm{CH}_{3}\right), 7.16(\mathrm{~s}, 1 \mathrm{H},-\mathrm{CH}), 7.18-8.15$ $(\mathrm{m}, 10 \mathrm{H}), 8.60-8.62(\mathrm{~d}, 1 \mathrm{H},-\mathrm{NH}), 10.15(\mathrm{~s}, 1 \mathrm{H}, \mathrm{Ar} \mathrm{OH})$. El-MS (m/z, \%): M $^{+} 336$ (37), 259.51 (83), 230.07 (100).

\section{Compound 4c: N-((4-chlorophenyl)(2-hydroxynaph- thalen-1-yl)methyl)acetamide}

Yield: $72 \%$, White solid. m.p. $235-237^{\circ} \mathrm{C}$, IR (KBr): v 3391, 2962, 2700, 2613, 1637, 1577, 2523, 1490,
1436, 1374, 1331, 1278, 1243, 1171, 1091, 819, 747, 588, $499 \mathrm{~cm}^{-1}$. ${ }^{1} \mathrm{H}$ NMR: (400 MHz, DMSO- $\left.d_{6}\right): \delta 1.98$ $\left(\mathrm{s}, 3 \mathrm{H},-\mathrm{CH}_{3}\right), 7.07(\mathrm{~s}, 1 \mathrm{H},-\mathrm{CH}), 7.09-8.48(\mathrm{~m}, 10 \mathrm{H}$, $\mathrm{ArH}), 8.49(\mathrm{~d}, 1 \mathrm{H},-\mathrm{NH}), 10.07$ (s, 1H, Ar OH). El-MS $(\mathrm{m} / \mathrm{z}, \%): \mathrm{M}^{+} 324.63$ (56), 264.41 (67), 230.98 (100), $202.11(12)$.

\section{Compound 4i: N-((4-chlorophenyl)(2-hydroxynaph- thalen-1-yl)methyl)benzamide}

Yield: $68 \%$, White solid. m.p. $186-188^{\circ} \mathrm{C}, \mathrm{IR}(\mathrm{KBr})$ : v 3398, 3062, 2785, 2289, 2607, 1896, 1777, 1692, $1570,1503,1346,1438,1485,1090,1014,813,747$, 584, 541, 526, $437 \mathrm{~cm}^{-1}$. ${ }^{1} \mathrm{H}$ NMR: $(400 \mathrm{MHz}$, DMSO$\left.d_{6}\right): \delta 7.23(\mathrm{~s}, 1 \mathrm{H},-\mathrm{CH}), 7.25-8.07(\mathrm{~m}, 15 \mathrm{H}, \mathrm{ArOH})$, $9.05(\mathrm{~d}, 1 \mathrm{H},-\mathrm{NH}), 10.40$ (s, $1 \mathrm{H}, \mathrm{ArOH})$. El-MS (m/z, \%): $\mathrm{M}^{+} 386.82$ (25), 265.08 (100), 231.14 (73), 202.11 (22), 104.81 (12). 


\section{Compound 4k: N-((3-nitro phenyl)(2-hydroxy- naphthalen-1-yl)methyl)benzamide}

Yield: $80 \%$, Pale yellow solid. m.p. $234-236^{\circ} \mathrm{C}$, IR $(\mathrm{KBr}): v$ 3375, 3271, 3054, 2971, 2390, 1958, 1738, $1816,1633,1577,1530,1504,1479,1438,1346$, $1307,1279,1058,927,812,733,654,591,524,447$ $\mathrm{cm}^{-1} .{ }^{1} \mathrm{H}$ NMR: $\left(400 \mathrm{MHz}\right.$, DMSO- $\left.d_{6}\right): \delta 7.24(\mathrm{~s}, 1 \mathrm{H},-$ $\mathrm{CH}), 7.26-8.10(\mathrm{~m}, 15 \mathrm{H}, \mathrm{ArH}), 9.15-9.17(\mathrm{~d}, 1 \mathrm{H},-\mathrm{NH})$, 10.43 (s, $1 \mathrm{H}, \mathrm{ArOH})$. El-MS (m/z, \%): $\mathrm{M}^{+} 397.6(14)$, 230.58 (100), 260.09 (55), 275.41 (69), 380.41 (62), 202.10 (57), 105.14 (66), 115.42 (20), 144.51 (18).

\section{CONCLUSION}

In conclusion, a new protocol for a novel and highly efficient methodology for the synthesis of amidoalkyl naphthols by one-pot condensation reaction of aromatic aldehyde, $\quad \beta$-naphthol and acetamide/benzamide catalysed by TFA has been established under ordinary laboratory conditions. This method offers several advantages such as high conversions, easy handling, clean reaction profile, simple work-up, and shorter reaction time, which makes it a useful and attractive process for the quick synthesis of amidoalkyl naphthols. In the present method, work-up procedure is very simple which includes washing of the reaction mixture with water and recrystallization from ethanol. Therefore, this method could be an attractive alternative to existing methods for the synthesis of biologically important amidoalkyl naphthols.

\section{ACKNOWLEDGEMENTS}

We wish to thank Head, Department of Chemistry, M. S. University of Baroda for providing research facilities. ALP is also thankful to UGC, New Delhi, India, for financial assistance.

\section{REFERENCES}

[1] Devi I, Bhuyan PJ. Sodium bromide catalysed one-pot synthesis of tetrahydrobenzo[b]pyrans via a three-component cyclocondensation under microwave irradiation and solvent free conditions. Tetrahedron Lett 2004; 45: 8625-27. http://dx.doi.org/10.1016/j.tetlet.2004.09.158

[2] Knapp S. Synthesis of Complex Nucleoside Antibiotics. Chem Rev 1995; 95: 1859-76. http://dx.doi.org/0009-2665/95/0795-1859\$15.50/0

[3] Juaristi E. Enantioselective Synthesis of $\beta$-Amino Acids. New York: John Wiley \& Sons 1997.

[4] Shen AY, Tsai CT, Chen CL. Synthesis and cardiovascular evaluation of $\mathrm{N}$-substituted 1-aminomethyl-2-naphthols. Eur $\mathrm{J}$ Med Chem 1999; 34: 877-82. http://dx.doi.org/10.1016/S0223-5234(99)00204-4
Szatmari I, Fulop F. Syntheses and transformations of 1-( $\alpha-$ aminobenzyl)-2-naphthol derivatives. Curr Org Synth 2004; 1: 155-65.

http://dx.doi.org/10.2174/1570179043485402

[6] Gardner FE, Marth PC, Batjer LP. Spraying with plant growth substances to prevent apple fruit dropping. Science 1939; 90: 208-09.

http://dx.doi.org/10.1126/science.90.2331.208

[7] Archer TE, Stokes JD. Residue analysis of $\beta$ naphthoxyacetic acid and $\beta$-naphthol on field-sprayed tomatoes by high-pressure liquid chromatography. J Agric Food Chem 1980; 28: 877-80. http://dx.doi.org/10.1021/jf60230a011

[8] Kantevari S, Vuppalapati NVS, Nagarapu L. Montmorillonite K10-catalyzed efficient synthesis of amidoalkyl naphthols under solvent-free conditions. Catal Commun 2007; 8: 185762.

http://dx.doi.org/10.1016/i.catcom.2007.02.022

[9] Hossein M, Mohammad B, Majid H. Silica-supported perchloric acid (HClO4-SiO2):-A mild, reusable, and highly efficient heterogeneous catalyst for the synthesis of amidoalkyl naphthols. Chin Chem Lett 2008; 19: 1171-77. http://dx.doi.org/10.1016/j.cclet.2008.06.048

[10] Das B, Laxminarayana K, Ravikanth B, Rao RB. lodinecatalyzed preparation of amidoalkyl naphthols in solution and under solvent-free conditions. J Mol Catal A Chem 2007; 261: $180-88$

http://dx.doi.org/10.1016/j.molcata.2006.07.077

[11] Nagarapu L, Baseeruddin M, Apuri S, Kantevari S Potassium dodecatungstocobaltate trihydrate $\left(\mathrm{K}_{5} \mathrm{CoW}_{12} \mathrm{O}_{40}\right.$ $3 \mathrm{H}_{2} \mathrm{O}$ ): A mild and efficient reusable catalyst for the synthesis of amidoalkyl naphthols in solution and under solvent-free conditions. Catal Commun 2007; 8: 1729-34. http://dx.doi.org/10.1016/i.catcom.2007.02.008

[12] Khodaei MM, Khosropour RA, Moghanian H. A simple and efficient procedure for the synthesis of amidoalkyl naphthols by $p$-TSA in solution or under solvent-free conditions. Synlett 2006; 916-20.

http://dx.doi.org/10.1055/s-2006-939034

[13] Patil BS, Singh RP, Surpur PM, Samant SD. Ultrasoundpromoted synthesis of 1-amidoalkyl-2-naphthols via a threecomponent condensation of 2-naphthol, ureas/amides, and aldehydes, catalyzed by sulfamic acid under ambient conditions. Ultrason Sonochem 2007; 14: 515-18. http://dx.doi.org/10.1016/j.ultsonch.2006.09.006

[14] Patil BS, Singh RP, Surpur PM, Samant SD. Cationexchanged resins: Efficient heterogeneous catalysts for facile synthesis of 1-amidoalkyl-2-naphthols from one-pot, threecomponent condensations of amides/ureas, aldehydes and 2-naphthol. Synth Commun 2007; 37: 1659-64. http://dx.doi.org/10.1080/00397910701263858

[15] Shaterian $\mathrm{RH}$, Yarahmadi $\mathrm{H}$, Ghashang $\mathrm{M}$. An efficient, simple, and expeditious synthesis of 1-amidoalkyl-2naphthols as "drug like" molecules for biological screening. Bioorg Med Chem Lett 2008; 18: 788-92.

\section{http://dx.doi.org/10.1016/j.bmcl.2007.11.035}

[16] Su WK, Tang WY, Li JJ. Strontium(II) triflate-catalysed condensation of $\beta$-naphthol, aldehyde, and urea or amides: A facile synthesis of amidoalkyl naphthols. J Chem Res 2008; 3: $123-28$

http://dx.doi.org/10.3184/030823408X298508

[17] Shaterian $\mathrm{RH}$, Amirzadeh A, Khorami F, Ghashang $M$ Environmentally friendly preparation of amidoalkyl naphthols. Synth Commun 2008; 38: 2983-94. http://dx.doi.org/10.1080/00397910802006396

[18] Shaterian $\mathrm{RH}$, Khorami F, Amirzadeh A, Ghashang M. Preparation and application of perchloric acid supported on alumina $\left(\mathrm{Al}_{2} \mathrm{O}_{3}-\mathrm{HClO}_{4}\right)$ to the synthesis of $\alpha$-( $\alpha$-amidobenzyl)$\beta$-naphthols. Chin J Chem 2009; 27: 815-20.

http://dx.doi.org/10.1002/cjoc.200990136 
[19] Shaterian $\mathrm{RH}$, Yarahmadi H. Sodium hydrogen sulfate as effective and reusable heterogeneous catalyst for the onepot preparation of amidoalkyl naphthols. Arkivoc 2008; 2: 105-14.

http://arkat-usa.org/get-file/23225

[20] Chavan NL, Naik PJ, Nayak SK, Kusurkar RS. Indium(III) chloride: An efficient catalyst for the synthesis of amidoalkyl naphthols. Synth Commun 2010; 40: 2941-47. http://dx.doi.org/10.1080/00397910903340702

[21] Wang M, Song ZG, Liang Y. Zinc benzenesulfonatepromoted eco-friendly and efficient synthesis of 1-amidoalkyl2-naphthols. Synth Commun 2012; 42: 582-88. http://dx.doi.org/10.1080/00397911.2010.527424

[22] Shaterian $\mathrm{RH}$, Hosseinian A, Ghashang M. PPA-SiO2catalyzed multicomponent synthesis of amidoalkyl naphthols. Synth Commun 2008; 38: 3375-89. http://dx.doi.org/10.1080/00397910802138231

[23] Shaterian $\mathrm{RH}$, Yarahmadi H. A modified reaction for the preparation of amidoalkyl naphthols. Tetrahedron Lett 2008; 49: 1297-300. http://dx.doi.org/10.1016/i.tetlet.2007.12.093
[24] Selvam PN, Perumal TP. A new synthesis of acetoamido phenols promoted by $\mathrm{Ce}\left(\mathrm{SO}_{4}\right)_{2}$. Tetrahedron Lett 2006; 47 : 7481-83. http://dx.doi.org/10.1016/i.tetlet.2006.08.038

[25] Ansari SAMK, Sangshetti JN, Kokare ND, Wakte PS, Shinde DB. Oxalic acid-catalyzed solvent-free synthesis of $\alpha$ amidoalkyl- $\beta$-naphthols. Indian J Chem Technol 2010; 17: 71-73.

http://dx.doi.org/nopr.nicair.res.in/bitstream/123456789/7278/ 1/IJCT 17(1) 71-73

[26] Nandi GC, Samai S, Kumar R, Singh MS. Atom-efficient and environmentally friendly multicomponent synthesis of amidoalkyl naphthols catalyzed by $\mathrm{P}_{2} \mathrm{O}_{5}$. Tetrahedron Lett 2009; 50: 7220-22. http://dx.doi.org/10.1016/j.tetlet.2009.10.055

[27] Hajipour AR, Ghayeb Y, Sheikhan N, Ruoho AE. Bronsted acidic ionic liquid as an efficient and reusable catalyst for one-pot synthesis of 1-amidoalkyl 2-naphthols under solventfree conditions. Tetrahedron Lett 2009; 50: 5649-51. http://dx.doi.org/10.1016/j.tetlet.2009.07.116 